\title{
GROUP DEVELOPMENT PLAY IN THE DANCE MOVEMENT
}

\author{
Rr. Ruth Hertami DN ${ }^{*}$, Dilinar Adlin ${ }^{1}$, Deo Demonta Panggabean ${ }^{2}$
}

\author{
${ }^{1}$ Dance Education Study Program, Language and Arts Faculty, Medan State University, Medan, Indonesia \\ ${ }^{2}$ Physics Education Study Program, Faculty of Mathematics and Natural Sciences, Medan State University, Medan, \\ Indonesia \\ *Corresponding Author: hertamiruth@yahoo.com
}

\begin{abstract}
The movement that had been carried out in Early Childhood Education (PAUD) in the Cahaya and Manca playgroups in Delitua village was only on gymnastics or sports. The most basic cause is the absence of competent teachers in the field of dance movement. In addition, the available teachers do not understand optimally about how to provide dance material that is right at the age of the children in the playgroup. Based on this situation, the proposed team through the Coaching of Playgroups in Dance Motion, fostering and strengthening dance activities for children Light playgroups, as well as four teachers in the Manca playgroup. The method applied is guidance and stabilization of mastery of dance movements for the age of children, namely: (1) Butterfly dance which includes hand, foot, head, shoulder and hip movements, and (2) Flower Party dance which includes motion hands, feet, head, shoulders, and hips. Through this guidance and consolidation, 2 (two) new dances appeared, which were appropriate for the age of the children and packaged in audiovisual media, so that they could be used as learning media in the two playgroups.
\end{abstract}

Keywords: Playgroup, Butterfly dance, Flower Party dance.

\section{PRELIMINARY}

Early childhood education (PAUD) is a form of education aimed at children from birth to the age of six (6) years. Included in the PAUD category are kindergarten (TK), Raudatul Athfal (RA) and playgroups. PAUD is a form of education that focuses on stimulating education on growth and five (5) physical and spiritual development of children, namely: a) moral and religious development; b) physical development (fine and rough motor coordination); c) intelligence / cognitive (power of thought, creativity); d) socioemotional (attitude and emotion); and e) language and communication, according to the age group passed by early childhood as stated in the Minister of Education Regulation no. 58 of 2009. The five developments should fulfill 10 principles, such as 1) oriented to the needs of children, 2) learning through play, 3) child-centered approach, 4) constructivism approach, 5) creative and innovative approaches, 6) environment conducive, 7) using integrated learning, 8) thematic development 9) using various media and learning resources, and 10) developing various life skills.

Art activities for early childhood are activities that are able to fulfill the ten principles above because they are able to provide valuable values for their growth and development. In this case, dance activities function as a means of expression, because children can dance with enthusiasm and joy; as a means of communicating, because through motion as body language, children can convey messages to their friends dancing; as a means of developing talent, because through art dance activities the teacher directs children to improve their abilities; and as a creativity tool, because children are stimulated to move according to their imagination. Thus, the main emphasis on art activities for early childhood is its function and not the result alone. Art activities in early childhood emphasize experiences that will foster aesthetic values in themselves so that as adults they become sensitive individuals who care about their environment.

Mekar Sari Village, Delitua District has five schools at the level of Early Childhood Education, two of which are: 1) Light Playgroups, and 2) Manca Playgroups. Both of these playgroups have yet to carry out art activities in their learning activities, but only limited to carrying out gymnastic activities for their motor activities. Thus, the ability to dance students in both playgroups is minimal.

Based on the partner's problems, the proposer team provides competent personnel in their fields to provide assistance and guidance, both practical dance to the balance of their physical movements. Thus, if there is an opportunity for an art performance or an art competition at the level of a playgroup, these two playgroups can get involved or take part in the activity. The forms of coaching that will be carried out are:

1. Guidance and stabilization of one form dance, namely Butterfly dance for all students in the Light Playgroup. 
2. Guidance and consolidation of one form dance, namely the Flower Party dance for four teachers in the Manca Playgroup, which is packaged in the form of audio-visual media (VCD).

\section{ACTIVITY METHOD}

Implementation of Playgroup Coaching in Dance Motion is divided into 2 (two) stages, namely:

a. Guidance stage

Guiding the motion of flying butterflies with swinging hands, small dances while tiptoeing, moving in a sagging motion, shaking and nodding, shaking the shoulders and hips.

b. Stabilization phase

Carry out the practice of dancing in full by using dance accompaniment songs. Continued by applying a simple floor pattern in the form of two straight lines, vertical and horizontal; and two curved, semicircular and full circles.

\section{IMPLEMENTATION EVALUATION}

Evaluation of the implementation of the program is carried out by the implementing team and partners throughout the activities, from coaching to stabilization. Evaluation is carried out by examining the results of partners, which is carried out during coaching and coaching so that everyday improvement in the implementing and partner performance systems is found. In addition, dance products produced in the form of Butterfly and Flower Party dance can be used as assets by partners, which can then be used as performance material or competitions.

\section{RESULTS AND DISCUSSION}

\subsection{Result}

The initial purpose of this service was to provide dance and dance training to students and teachers in two (2) playgroups in Delitua. Student training was conducted in the Light Playgroup, while teacher training was conducted in the Manca playgroup. In its development, the number of partners in which the activity took place increased by one, namely in the playgroup managed by the village head of Mekar Sari and located in the village office. This playgroup has only been established in the 2017-2018 school year, so this moment of devotion is also used as an opportunity to broaden the teachers and students in this playgroup.

The dance produced during the killing and strengthening process in the three playgroups are:

a. Butterfly Dance for students in the Light Playgroup.

b. Flower Party Dance for teachers in the Manca Playgroup

c. Happy Dance for students in the Village Office Playgroup

\subsection{Discussion}

The steps used in the implementation of this service are:

a. In the mentoring process, the implementing team uses the person online method (directly and face to face) in delivering the material, assisted by students involved. The guidance process is carried out for 4 weeks to learn dance movements without musical accompaniment and floor patterns, with time details 3 times a week, and each time using 1 (one) hour, other than that partners are asked to do independent exercises.

b. In the stabilization process, the implementing team is assisted by students using the performance method by using dance accompaniment music and applying 2 straight-line floor patterns (vertical and horizontal) and 2 curved line floor patterns (half circle and full circle). The stabilization process is carried out for four (4) weeks, with time details 3 times a week, and each time uses 1 (one) hour.

The implementation of the service activities carried out by the team went well. The participants of the activities and the venue for the activities were very supportive of the implementation of the entire program. The constraints faced were almost non-existent, except because suddenly the village head's mother asked the team to include village schools as part of community service activities. This made the implementing team add to the schedule of activities that did not prevent the previous schedule that had been agreed with the two previous partners.

This activity had a positive impact because through this training two partner play groups obtained dance material that had never been owned before. Likewise, with additional partner playgroups. From now on, both partner groups and additional partners can fill in the event if there are activities at the group play or PAUD level that include dance as event material.

\section{CONCLUSIONS AND RECOMMENDATIONS \\ 5.1 Conclusions}

This service activity has run smoothly and well. The implementation team can work together well, as well as the activity participants consisting of students and teachers from three partners. From the results of the activity, the light playgroup got one form of animal-themed dance, namely the Butterfly dance, which was controlled by direct students. The Manca playgroup gets a form of nature-themed dance, namely Bunga dance which is directly controlled by the 
teachers, which will later be used as teaching material. While the playgroup guided by the village as an additional partner, get a form of daily-themed dance that is Gembira dance for students.

\subsection{Recommendations}

Dance activities that are the focus of coaching and training activities in this service have been completed. The enthusiasm from the participants of the dedication activity needs to be responded to because when the activity takes place, the participants hope that this activity has not or not stopped. Therefore, it is expected that there will be other teams that can improve the mastery of dance material with different themes in these three playgroups

\section{ACTIVITY DOCUMENTATION}

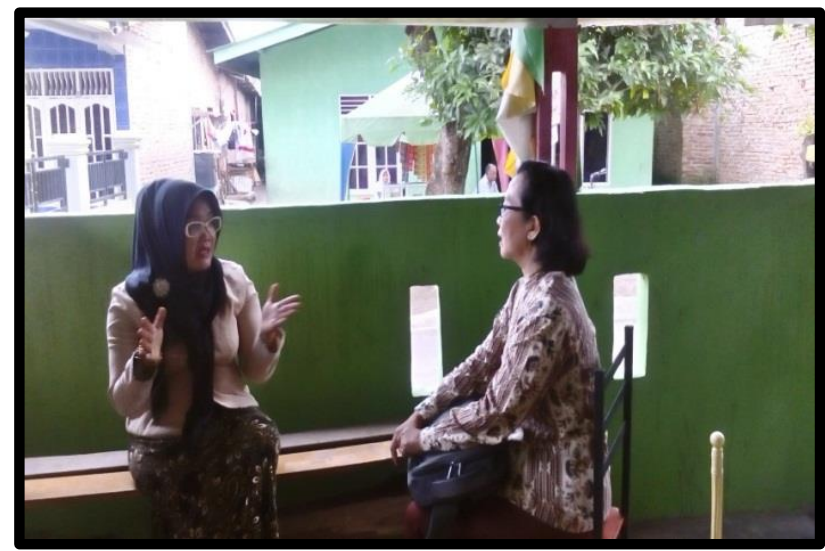

Figure 1. Discussion on the Establishment of a Training Schedule with the Principal of the Light Play Group.

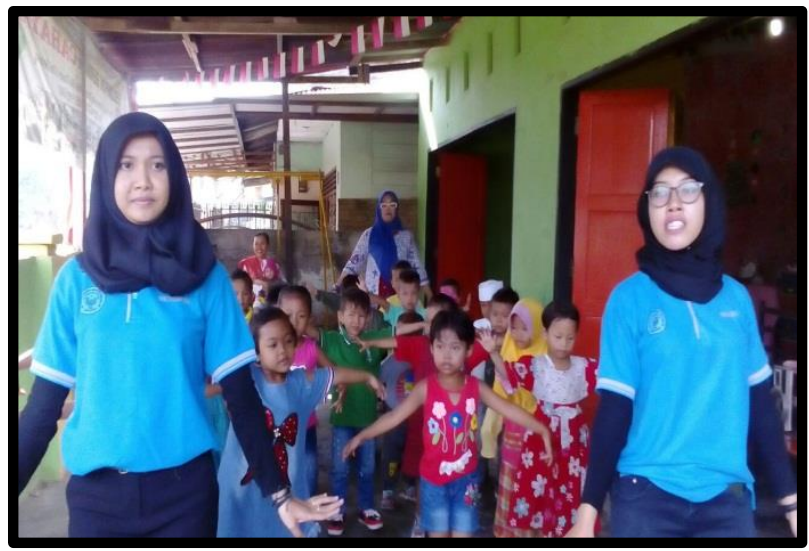

Figure 2. Guidance of Butterfly Dance with Students Involved in the Light Play Group.

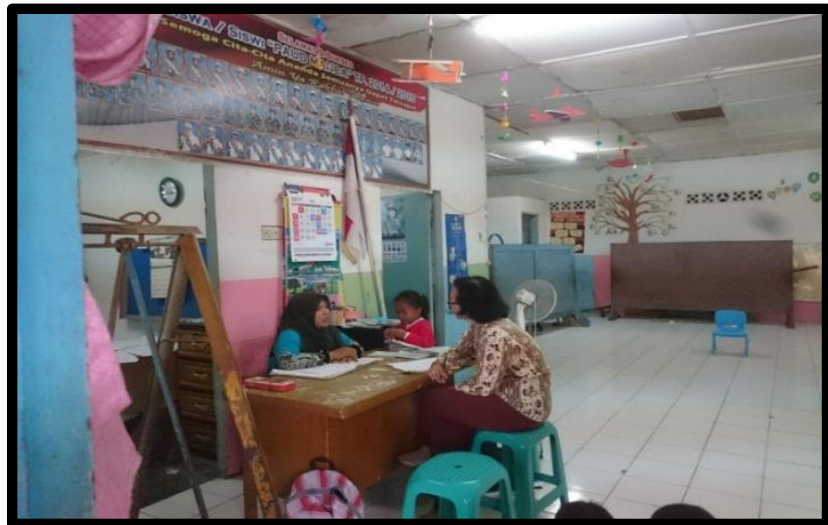

Figure 3. Discussion on Determination of Training Schedule with Manca Playgroup Principals 


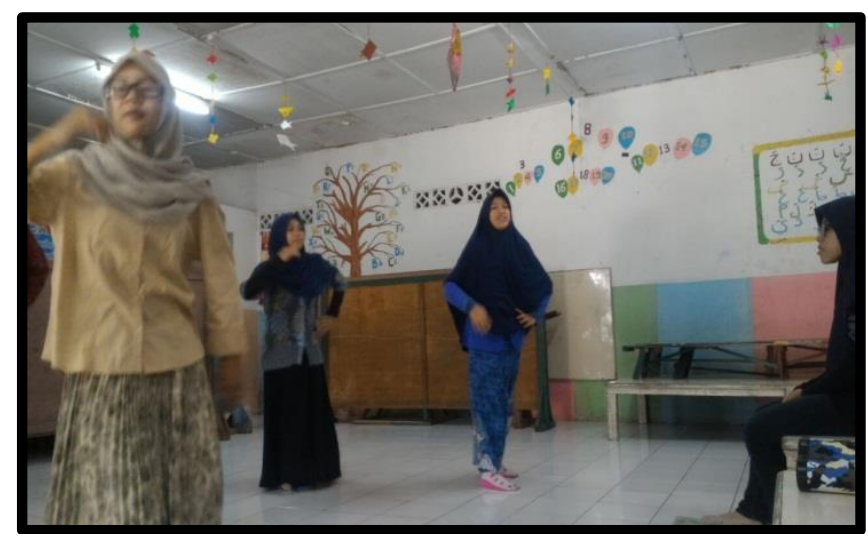

Figure 4. Guidance of Flower Party Dance with Students Who Are Included in the Manca Play Group.

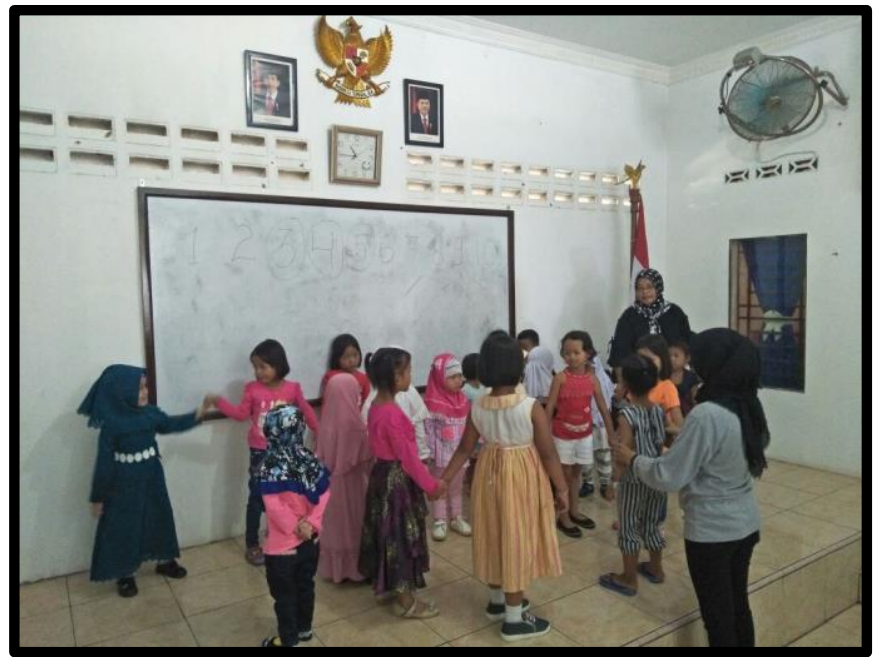

Figure 5. Guidance of Joyful Dance with Students Who Are Involved in the Play Group of Mekar Sari Village. 